\title{
Fujitsu and TI fight it out
}

\section{Tokyo}

MEL Sharp, senior vice president and general patent counsel for the US semiconductor manufacturer Texas Instruments, could barely conceal his frustration at a press conference in Tokyo last week when he described the battle he has fought with Japan for the past 27 years, trying to establish the US company's claim to a fundamental patent for integrated circuits.

The Texas Instruments press conference was held after the first hearings in a legal battle in the Japanese courts between the US company and Fujitsu of Japan over the Kilby patent. Texas Instruments claims that the patent - which describes the first primitive integrated circuit invented by Jack Kilby in the late 1950s - applies to all modern computer chips, and the company is demanding enormous licence fees from Fujitsu and other Japanese semiconductor manufacturers. But Fujitsu says the patent, which was finally granted in Japan in 1989, applies only to old technology no longer in use, and the Japanese company filed a suit in the Tokyo District Court on 19 July seeking a decision that the patent does not apply to Fujitsu chips. On the same day, Texas Instruments filed a kari shobun (injunctive relief) action to stop use, production and sale of all Fujitsu integrated circuits.

The patent dispute is crucial for the financial future of the two giant companies. It also draws attention to some of the fundamental differences between the US and Japanese patent systems and illustrates the growing importance of intellectual property rights in the struggle for technological supremacy between the United States and Japan.

Sharp says that when he first visited the Japanese patent office in 1964, he was dismayed to discover that the Kilby patent, filed in Japan in 1960 on the basis of the 1959 US application, was dormant. Nothing had happened for four years. After two days of intensive discussions with Japanese patent authorities, he decided that the only way to proceed was to break the patent up into several divisions because of a very basic difference between US and Japanese patent law.

At the time, under Japanese law, a patent could make only one claim, and, as a result, Japanese patents were (and still tend to be) very narrow in scope. In contrast, the initial Kilby patent awarded in the United States in 1964 had 25 claims. The Kilby invention ultimately led to five US patents with a total of 60 claims.

The first division of the Japanese patent application, numbered 320,249 , was published in 1965, and, after opposition by Japanese companies, was eventually granted in 1977; it expired three years later, or 15 years after publication. The only other division to survive - number 320,275 , the one now under contention was "rejected, and rejected, and rejected", Sharp says, until it was finally accepted for publication by the Japanese patent office in 1986. The patent was granted in 1989 and will expire in 2001.

The patent focuses on the two-dimensional layout of circuit elements and their interconnections in integrated circuits. Because only one claim per patent was allowed, Sharp says Texas Instruments had to be extremely careful in the selection of words in the patent description, because there was "just one chance" to be right. And the legal dispute between Fujitsu and Texas Instruments in fact centres on interpretation of only one or two words.

For example, where the patent says conductors are "laid down" on an insulator, Fujitsu argues that this means detachable wires on an insulator, as in the original Kilby circuit. But Sharp says it just means "conductor on insulator" and applies to the thin-film coatings of conductors used in modern chips.

At stake in this argument are tens of millions of dollars, and possibly the future of the two companies. Texas Instruments has recently gone into debt as it invests heavily to gear up for development and production of next-generation chips, in particular 16-megabit memory chips. Revenues from patents are a vital source of funds to do this. The company's quarterly income from patents now stands at about $\$ 40$ million, according to press reports, much of it coming from Japanese companies that have (reluctantly) accepted the validity of the Kilby patent.

Similarly, Fujitsu is investing heavily in next-generation memory chips to try to catch up with other Japanese manufacturers. And, unlike some of its Japanese competitors, Fujitsu does not have much leading-edge technology to barter in crosslicensing agreements with Texas Instruments. That is why, industry sources say, the company decided to fight in court.

Although other Japanese companies, such as NEC and Toshiba, have entered into licensing agreements with Texas Instruments, many people in Japanese industry are privately encouraging Fujitsu because they think the US company has become too greedy in trying to squeeze money out of old technology.

Sharp, on the other hand, sees the court battle as a test of the fairness of the Japanese patent system. The patent office has been "very fair" since 1986, he says, and "we prefer to focus attention on the past five years rather than the preceding twenty" in the belief a fair decision will be reached.

David Swinbanks

\section{SBIR is good business}

Washington

As the US government focuses more and more on the goal of commercializing federally funded research, there appears to be at least one programme that is meeting that objective. According to studies by the General Accounting Office (GAO) and the Small Business Administration (SBA) outlined last week, the Small Business Innovation Research (SBIR) programme has been highly successful in channelling research money to small companies that transform the research into commercial products.

Established in 1982, the programme mandates that any federal agency that spends more than $\$ 100$ million on outside research must set aside at least 1.25 per cent of its research funds for small companies working on projects with commercial potential. In fiscal year $1990, \$ 461$ million was spent on SBIR grants, more than 90 per cent of it coming from five agencies: the Department of Defense, the National Aeronautics and Space Administration, the National Institutes of Health, the Department of Energy and the National Science Foundation. Since its inception, the programme has directed $\$ \mathbf{2 , 2 0 0}$ million to 5,500 small companies.

The programme is scheduled to expire in $\mathbf{1 9 9 3}$ if not renewed by Congress.

The GAO found that up to the end of July, SBIR-funded research had led to $\$ 471$ million in sales for the companies receiving grants, and two-thirds of those sales have been to customers other than the federal government. The companies reported that they expect another $\$ 1,940$ million in sales by the end of 1993. The small businesses have also received extra, non-SBIR funding to develop the results of research paid for with the grants $-\$ 646$ million through July, with several hundred million more dollars expected by the end of 1993.

Furthermore, GAO judged that the quality of research has not suffered. The participating federal agencies reported that, on average, SBIR research was as good as or better than other contract research.

The SBA study, although differing in details from that of the GAO, agreed that the programme has been successful in encouraging commercialization of federal research.

One possible problem with the programme is that it could encourage 'proposal factories' - small research companies that file dozens or hundreds of SBIR proposals with little interest in commercializing the results. The GAO found some circumstantial evidence of this: on average, the companies that received five or more SBIR grants produced fewer sales and less extra developmental funding per project than did companies with fewer than five awards.

Robert Pool 